\title{
MODELANDO O MONISMO DE TRIPLO ASPECTO EM UM ESPAÇO DE ESTADOS COM DIMENSÕES FRACIONÁRIAS ${ }^{1}$
}

Alfredo Pereira Junior

Prof. Dr. do Departamento de Filosofia da Faculdade de Filosofia e Ciências - UNESP - Campus de Marília. Cientista Visitante no KEY Institute for Mind-Brain Research, vinculado à Universidade de Zurique. Pesquisador Visitante no Departamento de Psicologia da Universidade de Copenhagen e do Departamento de Ciências dos Fármacos da Universidade de Pavia.

E-mail: alfredo.pereira@gmail.com

Doutor em Engenharia e Professor Livre-Docente da Escola Politécnica da Universidade de São Paulo. E-mail: brescia@lexxa.com.br

\section{Enidio Ilario}

\begin{abstract}
RESUMO
A ontologia é uma disciplina filosófica que procura compreender os princípios subjacentes à organização da realidade. Além dos recursos conceituais tradicionais, uma teoria ontológica pode ser construída com o auxílio de ferramentas oriundas de contextos interdisciplinares. Neste estudo, utilizamos a Teoria de Sistemas e a ferramenta Espaço de Estados para modelar a ontologia do Monismo de Triplo Aspecto, teoria filosófica que entende a realidade como exaustivamente descritível em três aspectos superpostos: 1) Matéria/Energia,2) Forma/Informação e 3) Sentimento/Consciência. Considerando a hipótese naturalista de que as dimensões adicionais necessárias para representar o segundo e terceiro aspectos estão aninhadas no espaço-tempo quadridimensional formatado pelo primeiro aspecto, utilizamos o conceito de dimensão fracionária para representar o espaço de estados $\mathrm{N}$-dimensional da realidade em uma versão compacta, assim evitando a "inflação dimensional" que se tornou comum nas cosmologias contemporâneas.
\end{abstract}

\footnotetext{
${ }^{1}$ Agradecemos à FAPESP pelo apoio a esta pesquisa, por meio do Projeto Temático "Sistêmica, AutoOrganização e Informação" e Auxílio Individual (APJ) ao projeto "Monismo de Triplo Aspecto: uma filosofia interdisciplinar para o Séc. XXI"; e a Max Velmans por seus comentários construtivos a uma versão anterior deste trabalho.
} 
PALAVRAS-CHAVE: Sistemas complexos. Sistemas dinâmicos. Energia. Matéria. Informação. Consciência.

\title{
MODELING TRIPLE ASPECT MONISM IN A STATE SPACE WITH FRACTIONAL DIMENSIONS
}

\begin{abstract}
Ontology is a philosophical discipline that aims to understand the principles underlying the organization of reality. Beyond traditional conceptual resources, an ontological theory can be constructed with the help of tools from interdisciplinary contexts. In this essay, we use Systems Theory and the State Space tool to model the ontology of TripleAspect Monism, a philosophical theory in which reality is conceived as exhaustively describable in three superposed aspects: 1) Matter/Energy; 2) Form/Information and 3) Feeling/Consciousness. Taking into consideration the naturalist hypothesis that additional dimensions required to describe the second and third aspects are nested in the four dimensional spacetime formatted by the first aspect, we use the concept of fractal dimension to represent the N-Dimensional state space of reality in a compact version, thus avoiding the "dimensional explosion" that became a commonplace in contemporary cosmologies.
\end{abstract}

KEYWORDS: Complex Systems. Dynamic Systems. Energy. Matter. Information. Consciousness.

\section{DA ELABORAÇÃO ONTOLÓGICA}

As filosofias do vir-a-ser, iniciadas com Aristóteles (BODNAR, 2012) e representadas na contemporaneidade pela obra de Whitehead (1929), concebem a realidade como um conjunto de potencialidades que se combinam em atualizações temporárias, gerando os fenômenos por nós vivenciados e estudados cientificamente. A natureza empírica, objeto de observação e experimentação, seria constituída por atualizações daquelas potencialidades, compondo os estados dos sistemas, e suas alterações dinâmicas, os processos.

Na elaboração de uma ontologia, podemos usar recursos conceituais clássicos, como a Teoria de Categorias (ARISTÓTELES, 1963; HUSSERL, 1913a,b; HARTMANN 'apud'PETERSON, 2012; POLI, 2014; SMITH, 2003) e seus desdobramentos lógicos (SIMONS, 2015). Entretanto, a Teoria de Conjuntos clássica, cuja semântica de primeira ordem é representável em diagramas bidimensionais, não seria adequada para representar a complexidade da relação entre as categorias ontológicas do Monismo de Triplo Aspecto (MTA; PEREIRA JUNIOR, 2013), como discutido adiante. 
O MTA é uma teoria ontológica que entende a realidade como exaustivamente descritível em três aspectos superpostos:

1) Matéria/Energia;

2) Forma/Informação; e

3) Sentimento/Consciência.

Tal realidade não está pronta e acabada, mas em movimento e transformação; sua manifestação imediata se faz no aspecto físico da realidade, que é aquele estudado pelas ciências físicas e químicas. Entretanto, a realidade não se reduz ao aspecto físico, mas se desdobra progressivamente no tempo, podendo - ou não - se atualizar nos demais aspectos.

\section{O ESPAÇO DE ESTADOS DA NATUREZA}

A totalidade dos estados possíveis da Natureza (entendida como a totalidade da realidade) é representável por meio de um espaço de estados. Seguindo a sugestão de Brenner (2013), considera-se que os componentes elementares deste macrossistema são as Formas de Energia (FE), que se combinam para gerar os estados atualizados emergentes, com os quais podemos interagir empiricamente (PEREIRA; VIMAL; PREGNOLATO, 2016). As FE seriam semelhantes às minúsculas cordas da teoria M-String (GREENE, 1999). Não podemos observálas diretamente; percebemos apenas suas combinações, as quais constituem a realidade fenomênica.

Como não assumimos a concepção kantiana de distinção absoluta entre as formas a priori constituintes do sujeito cognitivo e a "matéria empírica" que preenche tal forma, entendese que, em última análise, as FE constituem tanto os conteúdos empíricos (nossas percepções das formas dos objetos e da matéria de que são feitos), quanto as formas cognitivas (atualizadas em nosso sistema nervoso) que utilizadas para representá-los nos âmbitos da filosofia e na ciência.

Inicialmente descrevemos como seria um espaço de estados $\mathrm{N}$-dimensional que contivesse todas as propriedades dos três aspectos da realidade. Nesta abordagem, $\mathrm{N}$ seria um número na casa de dezenas ou centenas. Para evitar tal "explosão dimensional”, propomos compactar o espaço Ndimensional utilizando o modelo de dimensões fracionárias aninhadas, recentemente desenvolvido como meio de compressão de informação em contextos 
pragmáticos (TRAINA JUNIOR et al., 2010; XU et al., 2015) e como ferramenta de modelagem dos aspectos superpostos da realidade (HO et al., 2015). Com este recurso, podemos representar as dimensões qualitativas dos processos informacionais e das vivências humanas enquanto aninhadas ('nested') no espaço-tempo da física, ou seja, representa-se as dimensões qualitativas como dimensões fracionárias de um espaço de estados quadridimensional.

A notação que introduzimos para definir tais dimensões consiste em números duplamente fracionários do tipo "X, YY, ZZZ”, onde $\mathrm{X}=4$ (espaço-tempo físico; primeiro aspecto do MTA), YY = dimensões qualitativas informacionais (segundo aspecto do MTA) e $\mathrm{ZZZ}$ = dimensões qualitativas conscientes (terceiro aspecto do MTA). Espera-se que esta inovação notacional seja útil para que se possa superar tanto as abordagens reducionistas (nas quais se reduz os aspectos informacional e consciente ao físico) quanto as dualistas ou trialistas (nas quais os aspectos da realidade são concebidos como totalmente disjuntos uns dos outros).

\section{O EMERGENTISMO FORTE NO MONISMO DE TRIPLO ASPECTO}

As formas elementares de energia (FE), que constituem o espaço de estados da realidade, são concebidas como eternas, permanecendo subjacentes a todas as atualizações que ocorrem ao longo do tempo. As atualizações, que correspondem a combinações dinâmicas das FE, estão localizadas no espaço-tempo físico, mas contém propriedades que não se reduzem às propriedades físicas. As combinações ocorrem em três fases, aqui chamado de aspectos (PEREIRA JUNIOR, 2013; 2014; 2015a).

Há uma ordem das atualizações: o segundo e terceiro aspectos dependem de condições adequadas (ou seja, de pré-requisitos) para serem realizados. O primeiro aspecto é uma atualização imediata das potencialidades da Natureza; é necessário como passo inicial do processo de vir-a-ser da realidade, mas este devir não se reduz ao aspecto físico. O segundo aspecto depende da prévia atualização do primeiro. O terceiro aspecto depende de uma atualização prévia do segundo.

Concebemos o processo de atualização como sendo fortemente emergente, incluindo um componente de "acaso" no sentido de Cournot (LUNGARZO; PEREIRA JUNIOR, 2009) e Debrun (DEBRUN, 1996; BATISTA et al., 2014). Os processos cournotianos são semideterminísticos, ou seja, aqueles nos quais linhas causais independentes interagem, fazendo 
emergir uma combinação inédita das FE, o que corresponde a um processo de emergência forte, no sentido de um padrão de organização que não poderia ser previsto a partir do estado temporal anterior da totalidade da realidade, e que traz consigo uma realidade fenomênica irredutível.

Uma analogia útil para este conceito de emergência forte se encontra na linguística generativa. Podemos gerar um número potencialmente infinito de palavras e sentenças novas a partir de um alfabeto finito, usando um número finito de regras. Do mesmo modo, propomos que o vir-a-ser da realidade engendra um número potencialmente infinito de combinações das FE elementares, que definem tanto a estrutura/funcionamento de nosso sistema nervoso quanto os conteúdos de nossas experiências fenomênicas.

As FE permanecem subjacentes a suas atualizações, como um substrato que possibilita a emergência forte de novas combinações, a partir do processo evolutivo já decorrido. Novamente a comparação com a linguagem humana faz sentido: aquilo que dizemos decorre tanto do alfabeto e regras utilizadas quanto das palavras e sentenças anteriormente proferidas. Podemos formalizar este tipo de processo como sendo de tipo markoviano com memória, gerando o que pode ser chamado de de padrões coletivos relacionais (LUNGARZO; PEREIRA JUNIOR, 2009).

\subsection{Primeiro Aspecto: Matéria/Energia}

A atualização material da energia engloba todos os processos que ocorrem no espaço/tempo de quatro dimensões. Segundo o modelo padrão da física, esta atualização requer um determinado tipo de interação entre as FE. Tais interações são descritas como ocorrendo entre partículas fundamentais, férmions e bósons.

A atualização imediata das potencialidades da natureza ocorre no mundo físico. A autoorganização do macrossistema de FE faz emergir as quatro forças físicas fundamentais (gravitacional, nuclear forte, nuclear fraca e eletromagnética). Os processos físicos, regidos por estas forças, levam à formação dos elementos químicos, representado na tabela periódica. Os elementos químicos se combinam para formar moléculas e substâncias, como estudado pelas ciências químicas. Um arranjo recorrente de macromoléculas enseja o surgimento dos primeiros sistemas vivos unicelulares, ou seja, aqueles que apresentam a atividade metabólica estudada pela citologia vegetal e animal. 


\subsection{Segundo Aspecto: Forma/Informação}

$\mathrm{O}$ segundo aspecto inclui tanto a forma intrínseca aos sistemas (a forma no sentido aristotélico) quanto a forma que se transmite entre sistemas físicos (ou seja, a informação - em seus aspectos sintáticos e semânticos). As qualidades das formas e da informação são representadas em dimensões do espaço de estados adicionais às quatro dimensões físicas.

$\mathrm{O}$ aspecto Forma/Informação emerge a partir do primeiro aspecto, concomitantemente ao processo evolutivo biológico. Todas as partículas físicas e compostos físico-químicos têm formas (configurações atômicas) e apresentam regularidades dinâmicas, mas a transmissão de formas entre dois ou mais sistemas macroscópicos, por meio de sistemas de sinais (formando linguagens, inicialmente na escala molecular) ocorre no domínio da comunicação entre células vivas.

No processo evolutivo, os componentes da Teoria da Informação (a fonte, o receptor e a codificação de mensagens) são originalmente recortados no contexto da atividade dos sistemas vivos; só mais tarde, no contexto da evolução humana, são instanciado em artefatos. Portanto, considera-se que os processos informacionais seriam contemporâneos aos processos biológicos em sistemas multicelulares.

\subsection{Terceiro Aspecto: Sentimentos/Consciência}

A realização de processos informacionais permite a constituição de sistemas cognitivos com especializações, tanto nos domínios biológicos quanto artificiais; porém, tais sistemas não são necessariamente conscientes; para tornarem-se conscientes, é necessário que aconteça a atualização de outro aspecto da realidade, aqui identificado como o sentir. Um sistema consciente é basicamente um sistema capaz de sentir a mensagem carregada nos processos informacionais.

O Sentimento/Consciência, como potencialidade, seria um aspecto fundamental da Natureza, que pode ser atualizado em qualquer região do espaço/tempo. Entretanto, tal conceito não implica na teoria filosófica do Panpsiquismo, pois a efetivação da consciência depende de atualizações anteriores do primeiro e segundo aspectos, além da satisfação de condições específicas (PEREIRA JUNIOR, 2015b). Portanto, para o MTA a consciência sobrevém da natureza, mas não a partir apenas do aspecto físico (PEREIRA JUNIOR, 2013). 


\section{A ABORDAGEM SISTÊMICA}

A teoria de sistemas, com a denominação atual de Sistêmica, é apresentada em seus aspectos fundamentais em Bresciani \& D’Ottaviano (2000). Os conceitos da Teoria do Sistema Geral, que constituem a base conceitual da técnica chamada Sistemografia, são encontrados em Le Moigne (1990a,b). As características desta técnica que são interessantes para o nosso propósito estão resumidas abaixo.

Ao se elaborar modelos de sistemas complexos - como aqueles que se encontram à distância do equilíbrio termodinâmico, e que interagem com o ambiente, captando um fluxo de energia utilizado para manter sua entropia estável - a atenção do pesquisador é freqüentemente conduzida para a existência de múltiplos níveis, irredutíveis, de organização. Um sistema complexo pode ser entendido como um processo que consiste em um conjunto de atividades sequenciais ou recorrentes, cada uma destas atividades sendo representada por um bloco (processador).

A atividade total de um sistema é representada por um conjunto de blocos processadores ligados entre si, sob a forma típica de um diagrama. Essa é uma representação gráfica que recebe a denominação de sistemografia, e que não deixa de ser um fluxograma do processo contido em um sistema, ou representativo do sistema objeto de estudo (para a sua concepção, análise ou simulação).

$\mathrm{Na}$ modelagem do sistema se utiliza a sistemografia como um instrumento de concepção, análise ou simulação de sistemas. Modelar é conceber uma imagem para a representação do objeto, que pode ser idêntica (semelhança máxima) ou análoga (semelhança reduzida). Formalmente a analogia pode ser dos seguintes tipos: isomórfico, homomórfico e polimórfico. Uma analogia isomórfica ocorre quando cada elemento do modelo (processador e conexões associadas) corresponde a um único elemento do objeto. Uma analogia homomórfica é uma construção na qual cada elemento do modelo corresponde a, pelo menos, um elemento do objeto; e uma analogia polimórfica é uma construção na qual cada elemento do objeto corresponde a, pelo menos, um elemento no modelo. Deve notar-se que, dependendo da natureza do sistema, diferentes observadores e modeladores podem desenhar e construir diferentes sistemógrafos. 
Na sistemografia o sistema complexo é concebido, analisado ou simulado por meio do seu desdobramento em três subsistemas, ou seja, o subsistema operacional, subsistema informacional e subsistema com decisão (ou decisional), que devem operar de modo integrado. As atividades operacionais (concretas ou abstratas) são concebidas, analisadas ou simuladas: as informações necessárias às operações, ou resultante das operações, são identificadas, e as atividades de decisão sobre as operações e com apoio nas informações são definidas.

A sistemografia facilita a análise dos processos, pois permite a representação e a descrição dos subsistemas (operacional, informacional e decisional), inicialmente de modo separado e posteriormente de modo superposto, levando em consideração a complexidade do sistema total. Desse modo, os processadores também são classificados como sendo operacionais, informacionais e decisionais; um mesmo processador pode pertencer a uma, a duas ou a três dessas categorias.

Os processadores são também classificados de acordo com o tipo de atividade elementar, ou seja, como processadores de forma, de espaço e de tempo, podendo um mesmo processador pertencer a um, a dois ou a três desses tipos elementares. O processador do tipo forma atua de modo transformar o objeto a ser processado (energia, matéria ou informação); essa transformação pode ser apresentar de modo concreto como uma efetiva mudança de forma física (de matéria e energia), ou abstrata como um cálculo matemático executado em uma informação apresentada de forma numérica ou algébrica. O processador do tipo espaço atua de modo a promover o deslocamento no espaço do objeto a ser processado, e pode ser ilustrado como tendo a atribuição de transportar matéria, transmitir energia e realizar a comunicação de informação. O processador do tipo tempo é aquele no qual o tempo deve ser considerado como um fator de influência importante na transformação, no deslocamento ou mesmo na permanência sem qualquer atividade do objeto.

A rigor qualquer atividade consome algum tempo, mas na modelagem trata-se de identificar se esse tempo é ou não relevante para a definição do tempo total de processamento. E mesmo quando não há qualquer atividade física, como no caso de estoque de matéria, armazenagem de energia e registro de informação, existe um tempo a ser considerado, que é o tempo de inatividade. Em alguns casos, nos quais os processadores de tempo são particularmente relevantes, pode-se introduzir uma indicação de um parâmetro de tempo para 
os processadores, com a atribuição de índices que possam indicar os tempos mínimos, médios e máximos de processamento.

Os processadores podem também ser classificados de acordo com os seus níveis de complexidade em uma escala arbitrária, que pode conter diferentes níveis, sendo que um processador de nível superior contém também as propriedades de outro de um nível inferior. Podese destacar particularmente três níveis de complexidade.

O primeiro nível se refere ao processador com decisão: este exerce uma atividade com capacidade de tomar decisão, com base em uma informação, que provoca uma ação, ou seja, um comportamento predefinido e conhecido. Neste caso, convém distinguir pelo menos dois tipos de sub-processadores que fazem parte do processador de decisão, os quais são interligados pelo menos por uma conexão circular (laço informacional): o processador de decisão com informação (que representa o projeto e a finalidade do sistema), e o processador operacional, que leva da decisão à ação.

O segundo nível se refere ao processador de coordenação: este processador é um sistema amplo que se articula segundo os três subsistemas integrados, ou seja, o decisional, o informacional e o operacional.

O terceiro nível se refere ao processador com auto-finalização: este processador passa a ter no seu sistema de coordenação um subsistema de finalização que lhe dá a capacidade de gerar os seus próprios objetivos, e de ter consciência da sua existência e identidade; e, ainda, esse objetivo no seu sistema de coordenação engloba o sistema de diagnóstico, e no seu sistema de operação o sistema de manutenção.

Os níveis organizacionais e funcionais acima - os processadores e respectivas atividades - correspondem, em linhas gerais, aos três aspectos da realidade identificados pelo MTA. O nível operacional inclui as características estruturais e funcionais do sistema, que lhe permitem realizar operações com a matéria/energia no espaço-tempo físico. O nível informativo corresponde à sinalização entre os sub-sistemas que transportam mensagens relevantes e úteis para as operações. O nível decisional apreende e usa as mensagens para agir sobre o nível operacional, definindo os caminhos (e respectivas metas) a serem alcançados. 


\section{REPRESENTAÇÃO DIAGRAMÁTICA DO MTA}

Utilizando-se um diagrama bidimensional para ilustrar extensões conjuntistas, a estrutura da realidade - conforme o MTA - pode ser visualizada no seguinte desenho (Figura 1):

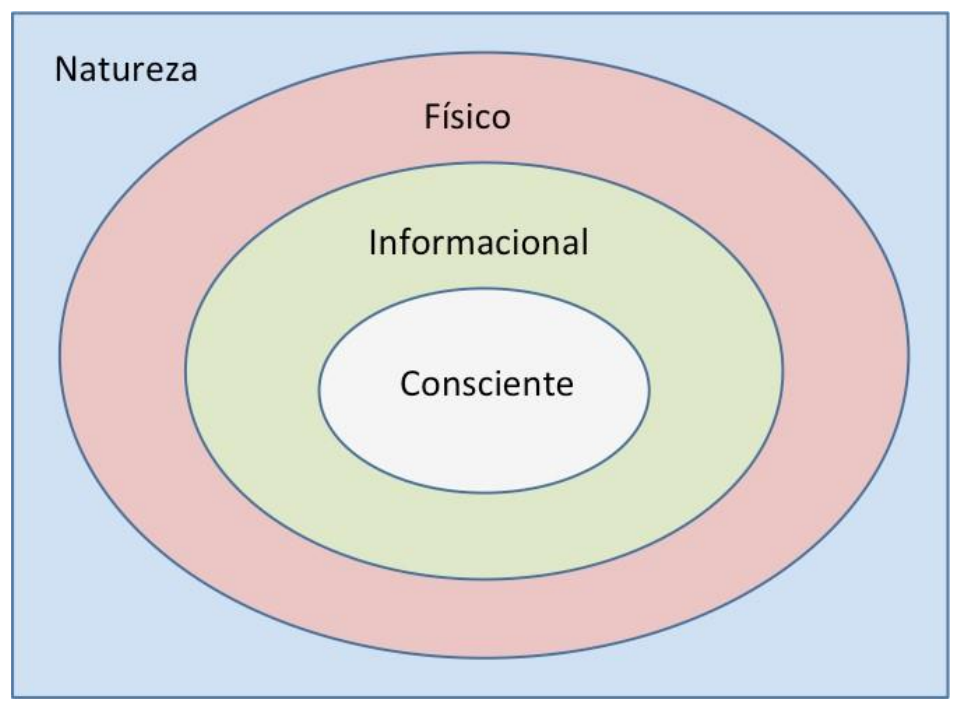

Figura 1- Esquema Básico da Estrutura da Realidade.

Fonte: Figura original elaborada por Alfredo Pereira Junior, 2016.

Segundo o MTA, a totalidade da realidade (Natureza) contém um conjunto de potencialidades que se atualiza em três aspectos, Físico, Informacional e Consciente.

O diagrama acima é uma representação estática da realidade conforme o MTA. Entretanto, como o processo evolutivo cósmico se caracteriza pela emergência forte do segundo e terceiro aspectos, a partir dos anteriores (e também das potencialidades eternas da Natureza), é preciso ainda representar as novidades, implícitas a cada aspecto, que não se reduzem aos aspectos anteriores.

Considerando que as propriedades dos sistemas físicos ocupam as quatro dimensões do espaço-tempo, a representação do segundo aspecto (em termos de características das formas/informações) requer dimensões adicionais, que emergem em continuidade com as dimensões do primeiro aspecto. Do mesmo modo, o terceiro aspecto requer novas dimensões adicionais para experiências conscientes (composto de cognições com sentimentos) que emergem em continuidade com as dimensões do segundo aspecto. 
Esse processo pode ser visualizado na figura 2, que simula uma estrutura tridimensional na qual as novidades emergentes do segundo e terceiro aspectos ocupam extensões adicionais:

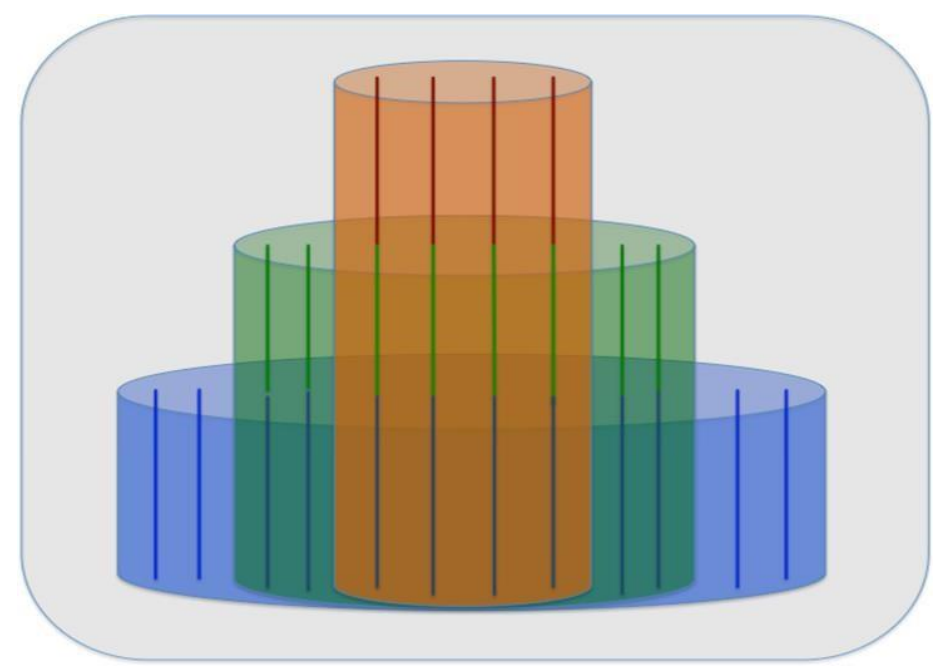

Figura 2 - O Bolo de Três Camadas na Caixa da Natureza.

Fonte: Figura original elaborada por Alfredo Pereira Junior, 2014.

Legenda: a) A caixa inteira: Natureza; b) Primeira camada (azul): aspecto físico; c) Segunda camada (verde): aspecto informacional; d) Terceira camada (laranja): aspecto consciente. As linhas coloridas indicam o enraizamento de cada aspecto nos anteriores, se projetando além deles. A experiência consciente requer a participação dos três aspectos em um processo contínuo e complementar.

Ambos os diagramas acima (das figuras 1 e 2) não oferecem uma representação diagramática perfeitamente adequada da estrutura do MTA, pois no primeiro as extensões emergentes não são representadas, enquanto no segundo são simuladas como externas aos aspectos anteriores. Para resolver esse problema lançaremos mão, na última seção deste estudo, do conceito de dimensão fracionária. Antes disso, é conveniente ilustrar quais seriam as dimensões adicionais ao espaço-tempo físico necessárias para se representar as propriedades dos fenômenos que se enquadram no segundo e terceiro aspectos.

\section{DIMENSÕES ADICIONAIS AO ESPAÇO-TEMPO FÍSICO QUADRIDIMENSIONAL}

Com a distinção entre qualidades primárias e secundárias na física moderna, a realidade física macroscópica - na qual se situam as qualidades primárias - foi representada no espaço 
tridimensional, com a adição de uma dimensão adicional de tempo. As qualidades secundárias foram historicamente excluídas do domínio de interesse das ciências físicas. Processos microscópicos, embora representados em um espaço de estados com mais de quatro dimensões, poderiam em princípio serem embutidos no espaço-tempo quadridimensional, apesar das conhecidas dificuldades para se integrar a teoria quântica com a relatividade.

Por uma questão de tradição histórica e simplicidade metodológica, assumimos que o aspecto físico da realidade pode ser representado no espaço-tempo quadridimensional, reservando a inclusão de dimensões adicionais para as propriedades correspondentes às qualidades secundárias - as quais, no MTA, são cobertas pelo segundo e terceiro aspectos da realidade.

Considerando-se a estrutura da transmissão da informação na teoria matemática de Shannon-Weaver, uma nova dimensão seria necessária para representar a quantidade de informação transmitida de uma fonte para um receptor. Ao se considerar também a semântica da informação (ou seja, a "diferença que faz a diferença" para o receptor em seu ambiente), é necessário introduzir mais dimensões, para representar a mensagem e sua respectiva interpretação da parte do receptor, o que se faria em um "espaço conceitual" (GARDËNFORS, 1990). Quantas dimensões seriam necessárias para o espaço conceitual de um receptor com as modalidades sensoriais e capacidades semânticas humanas?

Cada modalidade, para ser representada, requer o seu próprio espaço de estados. As estruturas destes espaços são provavelmente diferentes para diferentes espécies biológicas, mas não para indivíduos pertencentes à mesma espécie. O "espaço de cores" por nós percebidas foi originalmente concebido pelos alquimistas, e representado por Goethe como uma roda de duas dimensões (Figura 3). Na tecnologia de imagem contemporânea são utilizadas três cores fundamentais para compor um amplo espectro de tonalidades, como na tela de um monitor. A representação deste processo composicional em um espaço de estados demandaria uma estrutura geométrica tridimensional. 


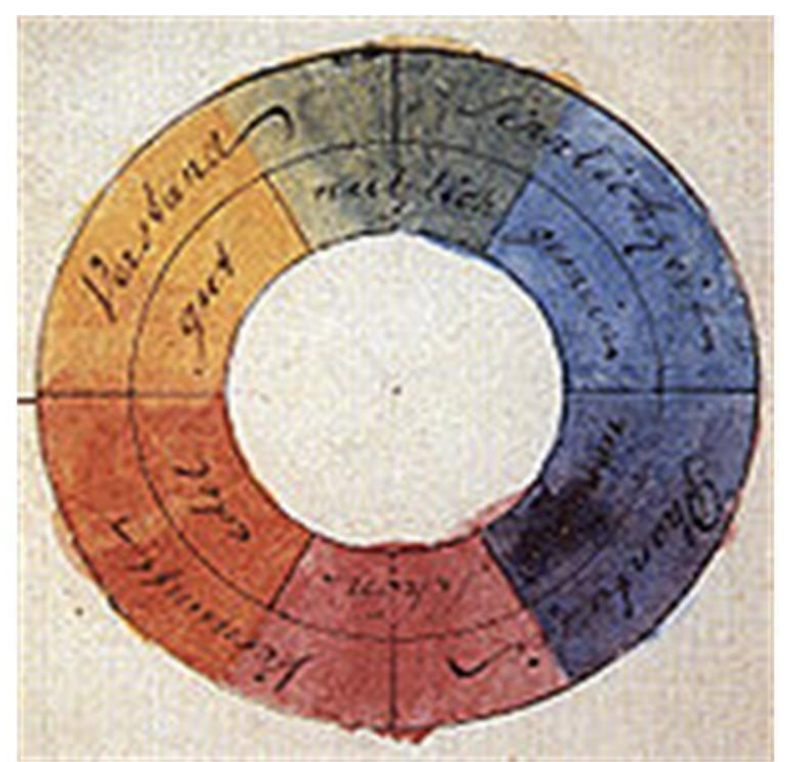

Figura 3 - Roda das Cores de Goethe

Fonte: Szcmphotography, 2013.

A roda é uma representação em duas dimensões do espaço de cores. Em abordagens contemporâneas, o espaço de cores é geralmente concebido como um espaço de estado tridimensional, onde cada dimensão corresponde a uma cor fundamental (vermelho, verde e azul): as combinações dessas 3 dimensões gerariam todas as cores.

A complexidade do espaço de estado da natureza aumenta com o terceiro aspecto, pois este se baseia em uma distinção conceitual entre significado (meaning) e sentimento (feeling). Para o MTA, a atribuição de significado pode ser inconsciente, como ocorre por exemplo no sistema imunológico, ao se distinguir o que é do sistema e o que deve ser interpretado como invasor (o antígeno), enquanto o sentimento é considerado como sendo a marca da consciência (PEREIRA JR, 2015a,b). Considerando-se que o significado de um padrão de informação é uma cadeia sígnica que é comumente associada ao padrão, e que o sentimento da mensagem é a reação afetiva singular de cada receptor a partir do significado atribuído, é preciso um novo conjunto de dimensões para representar o espaço de estados dos sentimentos conscientes.

Embora existam muitos tipos de sentimentos, sequer temos nomes específicos para cada um. Podemos distinguir quais seriam estes tipos:

- Sensações básicas, como fome, sede, frio;

- Sentimentos emocionais, como alegria e tristeza. No livro Ética, Spinoza identifica vários tipos de afetos, que correspondem ao nosso conceito de sentimentos 
emocionais. Para Spinoza, os afetos derivam de três tipos primitivos de sentimentos emocionais: dor, prazer e desejo. Muitos dos sentimentos emocionais têm uma dimensão social, no sentido de que necessitam de interações sociais como prérequisitos para serem atualizados, e remetem para objetos externos (como no caso das paixões);

- Sentimentos perceptuais, usualmente referidos pelo termo "qualia". Por exemplo, em 1927, Hans Hennings representou o espaço de estado de sabores (Figura 4);

- Sentimentos cognitivos: sentimentos amodais como "sentir que se sabe" algo, ou crenças de que determinadas proposições são verdadeiras;

- "O sentimento do que acontece" (DAMÁSIO, 1999), isto é, sentimentos ligados a eventos.

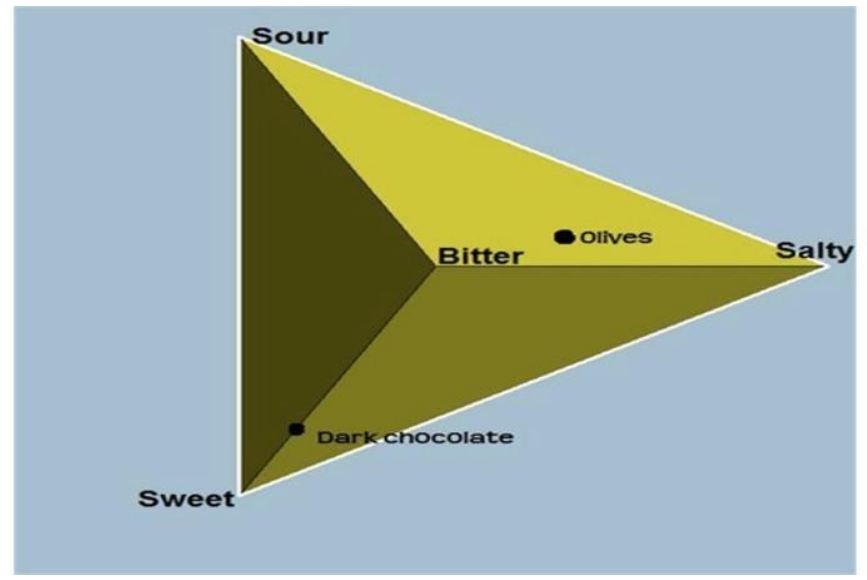

Figura 4 - O Tetraedro dos Sabores

Fonte: Adaptada de Gärdenfors, 2000.

As combinações das quatro dimensões do sabor (doce, salgado, amargo e azedo) produzem todas as nossas possíveis experiências gustativas, como, por exemplo, os sabores de chocolate e azeitona. 


\section{ANALOGIA COM O HIPERCUBO: INTERPRETAÇÕES IDEALISTA E NATURALISTA}

Um problema central na filosofia da consciência é a relação entre o espaço fenomenal, o espaço físico e o espaço ocupado pelo cérebro (VELMANS, 2009). Para filosofias idealistas subjetivas, o mundo físico (espaço-tempo quadridimensional) está contido no mundo consciente (espaço fenomenal), enquanto que para as filosofias idealistas objetivas ou absolutas o mundo físico está contido na mente de Deus ou consiste em subproduto de um Mundo de Idéias. Para as filosofias dualistas, os fenômenos conscientes não estão localizados no espaçotempo físico, mas sua locação não foi elucidada, o que seria justamente um dos maiores problemas deste tipo de ontologia. Para as filosofias fisicalistas reducionistas (chamadas de "Naturalismo Biológico") por Velmans (2009), o espaço fenomenal está localizado no cérebro, uma tese que conduz à consequiência indesejável que o crânio real (distinto do crânio fenomenal) seria maior do que a cúpula do céu (VELMANS, 2009).

$\mathrm{Na}$ abordagem filosófica aqui assumida, as propriedades de cada aspecto emergente não são redutíveis às propriedades dos anteriores. As dimensões dos espaços de estados dos aspectos emergentes não seriam topologicamente separadas das dimensões ocupadas pelos aspectos anteriores. Deste modo, as dimensões adicionais nas quais se representa as propriedades quantitativas e semânticas da informação devem estar aninhados no espaço-tempo quadridimensional da física, e as dimensões adicionais nas quais se representa as propriedades dos diversos tipos de sentimentos devem estar aninhadas nas dimensões informacionais.

Uma metáfora viável para este tipo de relação topológica é o Hipercubo (Figura 5), interpretando-se os cubos menores como um "aumento de densidade" do espaço ocupado pelos cubos maiores - o que procuraremos, em seguida, ilustrar pelo uso de dimensões fracionárias. O conceito de hipercubo foi possivelmente introduzido por Abbott (1884) no livro "Flatland" (LACHMAN, 2003). 


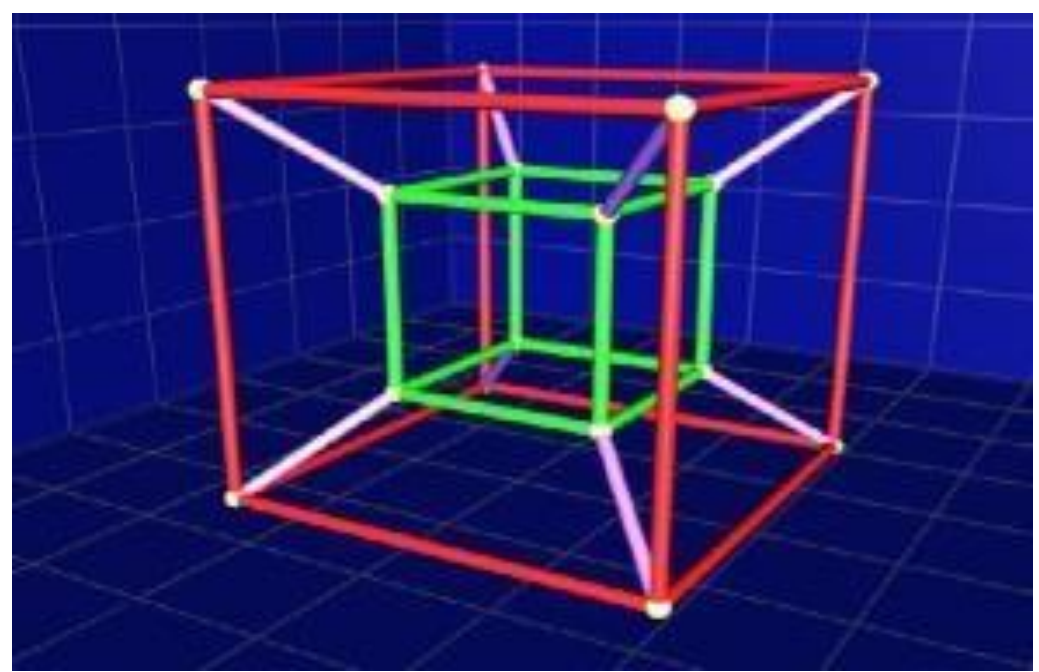

Figura 5 - O Hipercubo

Fonte: Silvestre, [s.d.].

Na visão idealista, o cubo vermelho é o Mundo Platônico das Ideias (ou a Mente de Deus), e o cubo verde no seu interior é a Natureza. Na visão naturalista aqui adotada, o cubo vermelho representa o espaço-tempo físico e o cubo verde representa o espaço fenomenal, onde as qualidades subjetivas de experiência consciente estão localizados em Silvestre (s.d.).

Para se representar o MTA, o hipercubo se compõe de três cubos, um para cada aspecto da Natureza. O primeiro aspecto é representado pelo cubo maior; o segundo aspecto é representado pelo intermediário, e o terceiro pelo menor. A Figura 6 ilustra os três cubos do MTA, que formam uma estrutura aninhada similar ao brinquedo de bonecas russas.
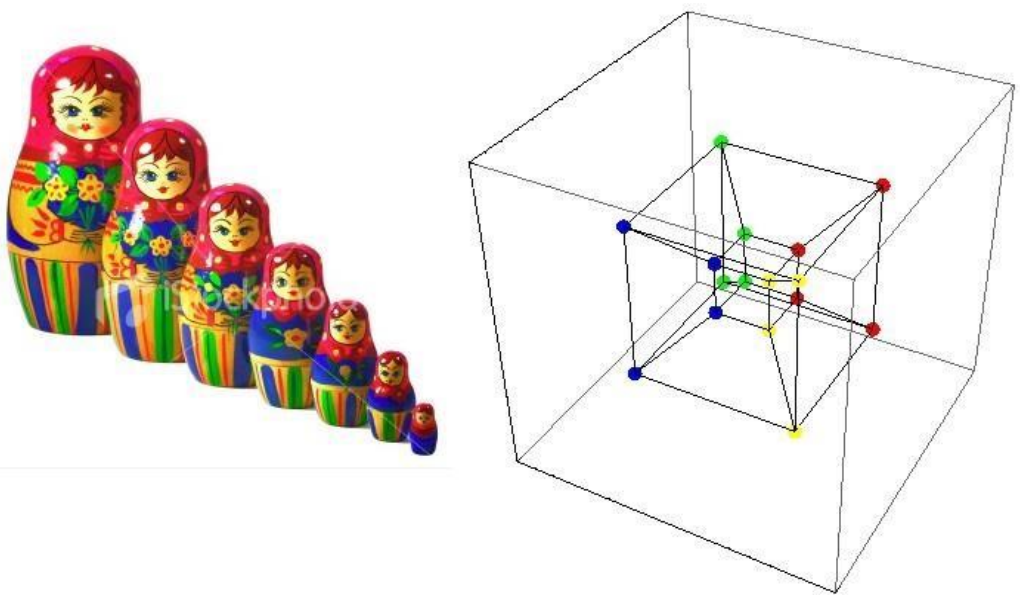

Figura 6 - O Hipercubo do MTA e as Bonecas Russas Fonte: Gestalt Reality, 2013. 
Estruturas tridimensionais (cubos) podem ser aninhadas em outros cubos, assim como as bonecas russas são inseríveis umas dentro das outras.

\section{O PROBLEMA DA INFLAÇÃO DIMENSIONAL E O RECURSO DAS DIMENSÕES FRACIONÁRIAS}

Como representar as novas dimensões que emergem no processo de vir-a-ser da realidade? Uma vez que um aspecto não pode ser reduzido a outros, e cada aspecto tem diversas propriedades que requerem, para serem representadas, dimensões próprias, há um risco de que o modelo tenda para dimensões infinitas, o que não seria adequado como reconstrução filosófica de nossa apreensão intuitiva da realidade. Este é o problema da inflação dimensional.

Se as dimensões adicionais ao primeiro aspecto, necessárias para representar as propriedades dos fenômenos pertencentes ao segundo e terceiro aspectos, forem representadas em dimensões adicionais separadas do espaço-tempo físico, pode-se recair no dualismo de tipo cartesiano, ou no dualismo de propriedades de Chalmers (1995; 1996), em que as propriedades físicas e mentais ocupam domínios disjuntos. A utilização de dimensões fracionárias permite uma solução elegante para o problema da "inflação dimensional", considerando-se as dimensões aninhadas como regiões de "maior densidade" internas às quatro dimensões físicas que constituem o quadro mais abrangente no qual os processos ocorrem.

As estruturas aninhadas podem ser abordadas por meio de ferramentas matemáticas que permitem a elaboração de representações numéricas. A primeira estratégia que vem à mente é o uso de dimensões fracionárias. Por exemplo, a curva de Koch (Figura 7) é uma figura representável numericamente por meio de dimensão fracionária. A operação para gerá-la começa com um triângulo equilátero; em seguida, cada lado do triângulo é dividido em três partes; a parte central gera outro triângulo equilátero, formando uma figura com quatro partes iguais; o número de elementos idênticos é 4, a relação de homotetia é 3 , e, por conseguinte, sua dimensão fracionária é aproximadamente igual a 1,26 (D = $\log (4) / \log (1 / 1 / 3)=1,262 \ldots)$. 


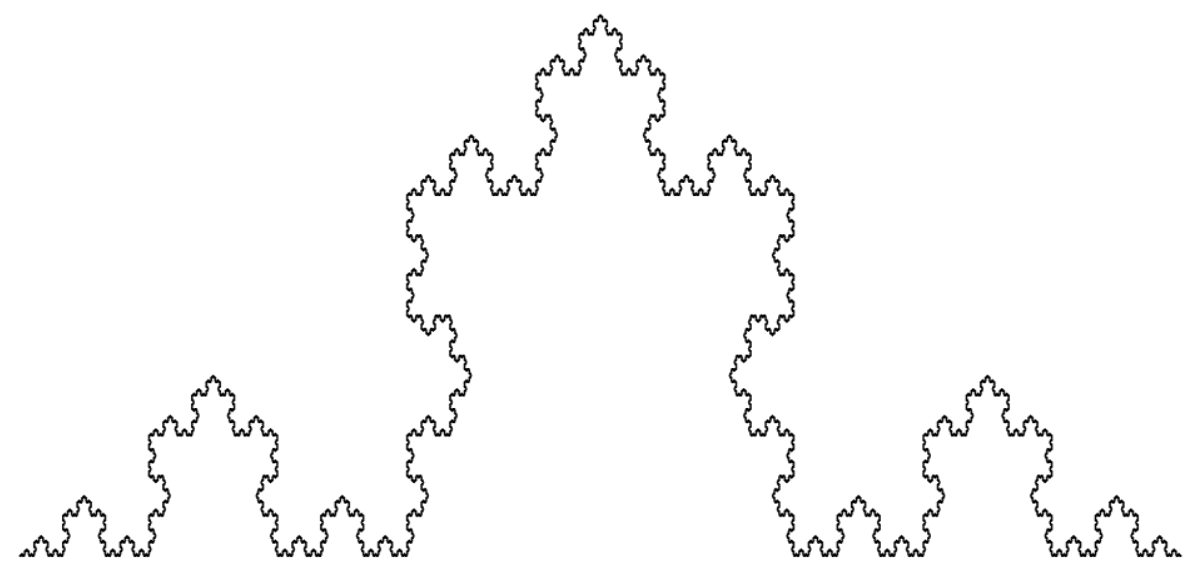

Figura 7 - A Curva de Koch.

Fonte: Wikimedia, [s.d].

A dimensão espacial física da figura é 1, enquanto que a dimensão fractal (representado pelo número após a vírgula $=262 \ldots$ ) refere-se à forma (segundo aspecto) da figura, que também pode ser medida utilizando-se o método "box counting".

Podemos representar processos informativos por meio de dimensões fracionárias adicionadas às dimensões físicas inteiras, como no exemplo acima - levando-se ainda em conta que em um processo de transmissão de informação um determinado padrão é instanciado duplamente, ou seja, tanto na fonte como no receptor. Um processo informativo pode ser concebido, no contexto da teoria matemática de Shannon e Weaver, como a transmissão de uma forma ("mensagem") entre uma fonte e um receptor. Esta operação implica que um padrão inicialmente instanciado na fonte de informação é reproduzida na estrutura de material do sistema do receptor. Além da representação probabilística habitual, este processo pode ser representado numericamente. No sistema maior, composto pela fonte e pelo receptor, a dimensão fracionária do padrão instanciado na fonte é dobrado. No caso de a transmissão da curva de Koch de uma fonte para um receptor, o sistema fonte-receptor teria a dimensão fracionária1, 524.

Como representar numericamente as dimensões necessárias para o terceiro aspecto, as inserindo dentro do segundo? Propomos uma convenção, usando duas vírgulas na mesma representação numérica, da seguinte forma: X, YY, ZZZ. Os dois primeiros dígitos após a primeira vírgula (YY) referem-se ao segundo aspecto, enquanto os três dígitos após a segunda vírgula $(\mathrm{ZZZ})$ referem-se ao terceiro aspecto. Por exemplo, o estado de um sistema consciente 
seria representado por 4, YY, ZZZ dimensões, onde o "4" refere-se a seu estado físico (que ocupa 3 espaciais e uma dimensão temporal), YY refere-se a seu estado informacional (as informações armazenadas e processadas pelo sistema) e ZZZ refere-se a seu estado de consciência (seus sentimentos e processos cognitivos a eles relacionados).

Da mesma maneira:

- O estado de um sistema macroscópico em equilíbrio termodinâmico (para o qual o tempo não é uma dimensão relevante) é representado em 3 dimensões inteiras;

- O estado de baixa entropia de um sistema macroscópico que atualiza apenas o aspecto físico é representado em 4 dimensões inteiras;

- O estado de um sistema no qual há processamento de informação é representado por 4, YY. Neste caso, considera-se YY como sendo diferente de zero.

Outro recurso que pode ser usado para compactificar as dimensões seria o uso de coordenadas não ortogonais. Esta estratégia pode ser expandida para o uso de planos ArgandGauss, por exemplo, para se abranger o grande número de combinações de sentimentos fundamentais que podem ocorrer em nossas experiências conscientes, relacionando-os com números imaginários. Não temos condições de desenvolver aqui este método de representação dos estados conscientes, mas fica registrada a sugestão, para quem estiver interessado em desenvolver tal modelo.

\section{COMENTÁRIOS FINAIS}

Em nossa construção de um modelo para a ontologia do MTA, ao espaço tridimensional macroscópico dos processos físicos foi inicialmente adicionada uma quarta dimensão que é a do tempo, compondo a estrutura quadridimensional utilizada para se representar o primeiro aspecto. Esta estrutura é numericamente representada por números inteiros de um dígito (X). Como é trivial na geometria elementar, considera-se que uma linha tem uma dimensão, um plano tem duas dimensões, o sólido tem três dimensões e sistemas para os quais o tempo é relevante para a análise têm quatro dimensões.

Propomos em seguida que esta estrutura quadridimensional inclua dimensões fracionárias, necessárias para representar as propriedades de sistemas que atualizam o segundo e terceiro aspectos. As dimensões fracionárias do segundo aspecto são representados por 
números de dois dígitos (YY) colocadas após a vírgula, e as dimensões fracionárias do terceiro aspecto são representadas por números de três dígitos (ZZZ) colocados após uma segunda vírgula, da seguinte forma: X, YY, ZZZ.

Em nossa tentativa de representar o espaço de estados da Natureza (a totalidade da realidade) de acordo com a TAM, a estrutura máxima resultante é um espaço-tempo quadrimensional que contém dimensões adicionais aninhadas. Esta abordagem indica um método para superar a dicotomia clássica do materialismo e do idealismo. Apesar de ser concebido em oposição às abordagens idealistas, o nosso modelo monista não tenta reduzir a Natureza a seu aspecto material. Ele inclui a Forma/Informação e o Sentimento/Consciência como aspectos fundamentais da Natureza, que emergem de suas potencialidades.

A diferença maior de nosso modelo frente aos modelos dualistas e idealistas da realidade é que o segundo e terceiro aspectos são considerados como aninhados dentro do primeiro. $\mathrm{O}$ uso de dimensões fracionárias e a analogia do hipercubo são sugeridos como meios de se representar a estrutura complexa da realidade, sem duplicá-la em dois ou três domínios separados (o que é assumido nas filosofias dualistas e trialistas) e sem negar a existência de uma realidade independente da(s) mente(s) (negação esta que ocorre nas filosofias idealistas).

\section{REFERÊNCIAS}

ABBOTT, Edwin A. (1884). Flatland: A D'Ottaviano, I.M.L.; Gonzales, M.E.Q. (Org.). Romance in Many Dimensions. New York: Auto-Organização. Coleção CLE-Unicamp 30, Dover, 1992.

Campinas, SP: Ed. UNICAMP, 2000.

ARISTOTLE. Categories. Trad. J. L. Ackrill. Oxford: Clarendon Press, 1963.

BODNAR, I. Aristotle's Natural Philosophy. In: The Stanford Encyclopedia of Philosophy (Spring 2012 Edition), Edward N. Zalta (ed.), Disponível em:

<http://plato.stanford.edu/archives/spr2012/entrie s/aristotle-natphil/>. Acessado em: 21 de Abril de 2016.

BRENNER, J. Lógica na Realidade. São Paulo: Ed. Triom, 2013.

BRESCIANI Filho, E.; D'OTTAVIANO, I. M. L. Conceitos básicos de sistêmica. In:
CHALMERS, David. Facing up to the problem of consciousness. J. Conscious. Stud. v. 2, p. 200219, 1995.

. The Conscious Mind. New York: Oxford University Press, 1996.

DAMASIO, A. The Feeling of What Happens:

Body and Emotion in the Making of Consciousness. New York: Harcourt, 1999.

DEBRUN, M. O Conceito de Auto-Organização. Cidade: Campinas. Editora: Centro de Lógica Epistemologia da UNICAMP, 1996.

BATISTA, A., PEREIRA JR., A.; PALERMO, F. Michel Debrun em Botucatu, 1990: O Conceito de 
Auto-Organização. Simbio-Logias 7 (10), 2014, p. 119-133. Disponível em: <http://www.ibb.unesp.br/Home/Departamentos/ Educacao/SimbioLogias/michel_debrun_em_bot ucatu.pdf $>$. Acesso em: 21 de abr. 2016.

GARDENFORS, P. Conceptual Spaces. Cambridge, MA: MIT Press, 2000.

GESTALT REALITY, Hyper-dimensional fractal cube reality. 19 mar. 2013. Disponível em: <http://www.gestaltreality.com/2013/03/19/hyper -dimensional-fractal-cube-reality/>. Acesso em: 18 de set. 2015.

GREENE, B. The Elegant Universe: Superstrings, Hidden Dimensions, and the Quest for the Ultimate Theory. New York: W.W. Norton \& Company, 1999.

HO, Mae-Wan., EL NASCHIE, Mohamed; VITIELLO, Giuseppe. (2015) Is Spacetime Fractal and Quantum Coherent in the Golden Mean? The Global Journal of Science Frontier Research 15, 2015, 1-A: p. 61-80. Disponível em: <http://www.journalofscience.org/index.php/ GJSFR/article/view/1466>. Acesso em: 21 de abr. 2016.

HUSSERL, E. (1913a) Ideas: General Introduction to Pure Phenomenology, translated by W. R. Boyce Gibson, New York: Collier Books, 1962.

Logical Investigations $\left(2^{\text {nd }}\right.$ edition; 2 volumes), translated by J. N. Findlay, London: Routledge, 2000.

LACHMAN, G. A Secret History of Consciousness. London: Lindsfarne, 2003.

LE MOIGNE, J. L. La Théorie du Systeme Général: théorie de la modélisation. 2. ed., Paris: PUF, 1990a.

Complexes. Paris: Dunod, 1990 b.

LUNGARZO, Carlos; PEREIRA JR., Alfredo. A Cournotian Approach to the Emergence of
Relational Collectives. TECCOGS - Revista Digital de Tecnologias Cognitivas, n. 1, p. 1-17, 2009.

PEREIRA Junior, A. Triple-Aspect Monism: A Conceptual Framework for the Science of Human Consciousness. In A. Pereira Jr. \& D. Lehmann (Eds.), The Unity of Mind, Brain and World: Current Perspectives on a Science of Consciousness. Cambridge, UK: Cambridge University Press, 2013, p. 299-337.

. Triple-Aspect Monism: Physiological, mental unconscious and conscious aspects of brain activity. Journal of Integrative Neuroscience, 13(2), p. 201-227, 2014.

. O Conceito de Sentimento no Monismo de Triplo Aspecto. Kinesis Vol. VII, $\mathrm{N}^{\circ} 14$ (Edição Especial - Debate), 2015a, p.1-24. Disponível em: https://www.marilia.unesp.br/Home/RevistasElet ronicas/Kinesis/0_alfredopereirajr.pdf. Acesso em: 21 de abr. 2016.

. Réplica aos Comentários. Kinesis Vol. VII, N ${ }^{\circ} 14$ (Edição Especial - Debate), 2015b, p. 95-143. Disponível em: <https://www.marilia.unesp.br/Home/RevistasEle tronicas/Kinesis/11_ replicasalfredo.pdf $>$. Acesso em: 21 de abr. 2016.

; VIMAL, R. L. P; PREGNOLATO, M. Can Qualitative Physics Solve the Hard Problem? In: POZNANSKI, R.; TUSZYNSKI, J.; FEINBERG, T. (Eds.) Biophysics of Consciousness: A Foundational Approach. Singapore: World Scientific, 2016.

PETERSON, Keith R. Nicolai Hartmann's Philosophy of Nature. Scripta Philosophice Naturalis, v.2, p. 113-149, 2012.

SILVESTRE. Construindo um hipercubo. [s.d.]. Disponível em:

<http://www.silvestre.eng.br/astronomia/artigos/ bigbang/11/>. Acesso em: 7 de mai. 2016.

SIMONS, P. Stanisław Leśniewski. In: The Stanford Encyclopedia of Philosophy (Winter 
2015 Edition), Edward N. Zalta (ed.), 2015. VELMANS, M. Understanding Consciousness. Disponível em: London: Routledge, 2009.

<http://plato.stanford.edu/archives/ win2015/entries/lesniewski/>. Acesso em: $21 \mathrm{de}$ abr. 2016.

SMITH, B. Ontology. In: Blackwell Guide to the Philosophy of Computing and Information, Oxford: Blackwell, 2003.

SZCMPHOTOGRAPHY. AT01: Research Project / Case Study. July 7, 2013. Disponível em: <https://szcmphotography.wordpress.com/>. Acesso em: 18 de set. 2015.

WHITEHEAD, A.N. Process and Reality. An Essay in Cosmology. Gifford Lectures Delivered in the University of Edinburgh During the Session 1927-1928. Cambridge UK: Cambridge University Press, 1929.

WIKIMEDIA. Koch Curve [s.d]. Disponível em: <https://upload.wikimedia.org/wikipedia/commo ns/thumb/5/5d/Koch_curve.svg/2000pxKoch_cur ve.svg.png>. Acesso em: 18 de set. 2015.

XU, Y.; QUAN, Y.; ZHANG, Z.; LING, H.; JI,

TRAINA Junior. C.; TRAINA, A.; WU, L.; FALOUTSOS, C. Fast feature selection using fractal dimension. Journal of Information and Data Management, 2010, p. 3-16. Disponível em: <http://www.cs.cmu.edu/ christos/PUBLICATI ONS/sbbd2k.pdf $>$. Acesso em: 21 de abr. 2016. H. Classifying dynamic textures via spatiotemporal fractal analysis. Pattern Recognition 48 (10), p. 3239-3248, 2015. 
PEREIRA JUNIOR, Alfredo. BRESCIANI FILHO, Ettore; ILARIO, Enidio. Modelando o Monismo de Triplo Aspecto Em Um Espaço de Estados com Dimensões Fracionária. Complexitas - Rev. Fil. Tem., Belém, v. 1, n. 1, p. 78-100, jan.jun. 2016. Disponível em:< http://www.periodicos.ufpa.br/index.php/complexitas/article/view/3411>. Acesso em: 05 jul. 2016. 